\title{
Letter
}

\section{공중보건에 관한 법률이 제정 되어야한다}

\section{김혜경}

수원시 장안구 보건소장

\section{공중보건에 관한 법률 제정의 필요성}

인구고령화로 인한 만성병 증가와 이에 따른 급속한 의료비 증가, 2015년에 경험한 메르스와 같은 감염병으로 인한 공중보건위기상황에 대한 대비와 대응, 경제양극화로 인한 계층 내지는 지역 간 건강격차, 수년째 OECD 국가 중 1 위를 차지하고 있는 자살률 등 현재 우리가 직면하고 있는 공중보건 과제가 녹녹하지 않다.

환자 치료 중심의 의료대책만으로 이러한 문제를 해결할 수 없음은 누구라도 인정할 것이다. 건강증진, 질병예방 및 질병의 지속적인 관리가 가능한 공중보건정책이 강화되어야만 이러한 난제들을 해결할 수 있을 것이다. 그러나 우리나 라의 공중보건은 아직도 매우 취약한 실정이다. 이러한 상태를 개선하려면 어떻게 해야 할까?

공중보건을 강화하기 위한 방안 중 가장 시급히 다루어져야 할 사항은 공중보건의 정체성을 확립하는 일이라 생각한 다. 우리나라는 아직도 공중보건이 무엇인지에 대한 근본적인 성찰이 매우 부족하다. 공중보건에 대한 개념을 정의하고 공중보건의 책무가 무엇인지를 규정하기 위한 내부적 합의가 필요하다. 다음으로 다루어져야 할 것은 공중보건 담당자 들의 역량강화라 생각한다. 우리는 아직까지 공중보건전문가란 누구를 지칭하는지에 대한 정의가 없고, 이들 공중보건 전문가가 반드시 함양해야 할 핵심역량에 대해서도 규정한 바가 없다.

일제강점에서 벗어난 1945 년 미군정에 의해 근대적 공중보건이 도입된 지 어언 70 여년이 흐른 지금 우리나라에는 아 직도 공중보건에 관한 법률이 제정되어 있지 않다. 하루라도 빨리 공중보건에 관한 법률을 제정하여 이 법속에 공중보건 의 정의 및 책무를 규정하고 공중보건전문가란 누구를 지칭하는지와 이들이 반드시 갖추어야 할 핵심역량 및 양성체계 등에 대하여 규정해야 한다. 


\section{현행 보건 및 의료 관련 법률의 문제점}

현행 보건 혹은 의료에 관련된 법률에서 공중보건에 관한 사항을 잘 규정하고 있다면 굳이 새로운 법률을 제정할 필 요가 없을 것이다. 그러면 지금부터 공중보건에 관한 기존 법률들의 문제점을 살펴보도록 하자.

「보건의료기본법」 제3조에 보면 ‘보건의료’란 국민의 건강을 보호·증진하기 위하여 국가·지방자치단체·보건의료기관 또는 보건의료인 등이 행하는 모든 활동들이라고 정의하고 있다. 이 조항의 문제는 인구집단의 건강관리를 하는 공중보 건과 환자개인의 치료에 중점을 두는 의료를 명확하게 구분하지 않고 ‘보건의료’라는 한 단어로 표기하고 있어서 마치 하나의 개념인 것처럼 착각을 일으킬 수 있다는 점이다.

다음은 「공공보건의료에 관한 법률」을 살펴보겠다. 제2조를 보면 '공공보건의료’란 국가, 지방자치단체 및 보건의료기 관이 지역·계층·분야에 관계없이 국민의 보편적인 의료 이용을 보장하고 건강을 보호·증진하는 모든 활동이라고 되어 있다. 이 정의 역시 공중보건과 공공의료를 분리하지 않고 있으며 보건의료기본법과 별 차이 없이 개념에 대한 정의 없 이 단지 각 활동 주체의 건강과 관련된 활동이라고 애매하게 표현하고 있다.

「지역보건법」은 어떨까? 이법은 보건소의 설치 및 업무에 대해서는 규정하고 있으나 정작 지역보건이 무엇을 의미하 는지에 대해서 정의하고 있지 않다.

다음은 현행 법률에서 보건 및 의료 담당인력들에 대해 어떻게 정의하고 있는지 살펴보기로 하자. 「공공보건의료에 관 한 법률」 제2조(정의)에는 ‘공공보건의료인력’에 대한 정의가 아예 없으며 「지역보건법」 제2조(정의) 역시 ‘지역보건인 력’에 대해 규정하고 있지 않다.

「보건의료기본법」 제3조는 ‘보건의료인'이란 보건의료 관계 법령에서 정하는 바에 따라 자격·면허 등을 취득하거나 보 건의료서비스에 종사하는 것이 허용된 자로 규정하고 있다. 이 정의 역시 보건인과 의료인을 분리하지 않고 있다는 것과 해당 인력의 책무와 이 인력이 지녀야 할 핵심역량에 대해서는 전혀 규정하지 않고 단순히 자격 또는 면허를 지닌 사람 으로만 정의하고 있다는 점에서 한계를 지니고 있다.

「정신건강증진 및 정신질환자 복지서비스 지원에 관한 법률」 제17조 제1항과 제2항에 의하면 ‘정신보건전문요원’이란 정신건강 분야에 관한 전문지식과 기술을 갖추고 보건복지부령으로 정하는 수련기관에서 수련을 받고 보건복지부장관 으로부터 자격을 인정받은 사람으로서 그 전문분야에 따라 정신건강임상심리사, 정신건강간호사 및 정신건강사회복지 사로 구분하고 있는데 이 조항 역시 정신보건전문요원의 임무와 핵심역량에 대한 규정 없이 단지 자격 요건만을 말하고 있어 역시 문제가 있다.

한편 의료법은 어떨까? 의료법 제2조 제 1 항을 살펴보면 의료인이란 보건복지부장관의 면허를 받은 의사·치과의사·한 의사·조산사 및 간호사로 정의하였고 또 제 2 항에서는 각 종별에 따른 임무를 규정하고 있다는 점에서 지금까지 검토했 던 다른 법에 비하면 진일보한 측면이 있다.

지금까지 검토해 본 바에 의하면 현행 법률 어디에서도 공중보건에 대한 정의는 없으며 공중보건 전문 인력에 대한 정 의 역시 없음을 알 수 있다. 더 나아가 공중보건의 책무 및 공중보건 전문 인력의 책무 그리고 이를 수행하기 위한 공중 보건 전문 인력의 핵심역량 및 인력 양성체계 등에 관해서도 전혀 규정되어 있지 않음을 알 수 있다. 


\section{공중보건과 의료의 차이}

공중보건의 개념을 정립하기 위해서는 먼저 공중보건과 의료의 차이를 명확하게 인식할 필요가 있다. 우선 이 둘의 가 장 큰 차이는 대상이 다르다는 것이다. 공중보건은 개인이 아닌 인구집단의 즉 환자 개개인의 질병치료가 아닌 지역주민 의 건강수준 향상을 위한 포괄적인 활동을 의미한다. 두 번째로 공중보건은 통상 정부의 책무이며 그 재원은 정부예산 이기 때문에 효율성을 중시할 수밖에 없다. 따라서 비용이 많이 드는 치료 보다는 건강증진과 질병예방을 우선시한다. 또한 의료는 의료인과 환자 특히 의사와 환자 사이의 라포 형성이 절대적인 반면공중보건은 서비스 대상 집단, 민간 전 문가 및 행정당국의 참여와 협력 즉 파트너십을 중시한다는 점에서 의료와 구분된다〈Table 1〉.

\section{〈Table 1〉 Differences between Public Health and Medical Care}

\begin{tabular}{c|c|c}
\hline & Public Health & Medical Care \\
\hline Object & Population & Individuals \\
\hline Intervention & $\begin{array}{c}\text { Health Promotion, Disease Prevention, } \\
\text { Treatment, Rehabilitation }\end{array}$ & Treatment \\
\hline Subject & $\begin{array}{c}\text { Population, Health Care Experts, } \\
\text { Heath Care Authorities }\end{array}$ & Patients, Doctors \\
\hline
\end{tabular}

\section{선진 외국의 공중보건에 관한 정의와 공중보건 전문 인력의 핵심역량에 대한 정의}

\section{1. 공중보건의 정의 및 책무}

아직까지 우리나라에서는 정부는 물론 학계에서도 공중보건의 정의 내지는 책무에 대해 규정한 적이 없다. 참고로 미 국의 사례를 들어보려고 한다. 2013년 미국 CDC는 '공중보건'이란 사람들이 건강하게 살 수 있는 조건들을 보장하기 위하여 사회가 집단적으로 행하는 활동이라고 정의하였고 ‘공중보건의 책무’를 질병의 유행 및 전파의 예방, 환경적 유 해인자로부터의 보호, 손상예방, 건강행태 개선 및 강화, 재난대응 및 재난 회복을 위한 지역사회 지원, 서비스의 질과 접근성에 대한 보장이라고 규정한 바 있다. 우리도 이제는 정부의 주도하에 학계와 실무담당자가 참여하는 $\mathrm{T} / \mathrm{F}$ 를 구성 하여 폭넓은 의견수렴과 심도 있는 연구를 통해 우리 실정에 맞는 공중보건의 정의와 책무를 규정할 필요가 있겠다.

\section{2. 공중보건 전문 인력의 정의 및 핵심 역량}

공중보건 전문 인력이란 국가나 지방자치단체의 보건담당 부서에서 일하며 국가, 지역 및 인구집단의 건강수준 파악, 건강정책 개발 및 건강정책 평가, 공중보건사업 등을 담당하는 공중보건 전문가를 말한다. 미국 CDC 에서는 공중보 건 전문 인력의 핵심역량을 분석/사정능력, 정책개발 및 프로그램 기획 능력, 소통능력, 문화적 감수성, 지역사회 차원 의 실행 능력, 공중보건학적 기술, 재정계획 및 관리 능력, 리더십 및 시스템적 사고 능력 등으로 규정한 바가 있다. 공직 의사들을 대표하는 학회인 대한공공의학회는 2016년 T/F를 구성하여 공직의사들의 책무와 핵심역량을 규정하기 위해 연구를 진행하고 있는데 정부에서도 관심을 가지고 지원을 할 필요가 있으며 공직의사 이외의 타 직종의 공중보건 전문 인력에 대해서도 동일한 작업이 시작되어야 함을 지적하고 싶다. 


\section{맺음말}

인구고령화, 만성질환증가, 심화되는 건강격차, OECD 1위인 자살률 등 우리가 해결해야 할 공중보건학적 과제가 산 적해 있다. 그러나 제대로 된 법률 하나 없을 정도로 우리의 공중보건 현실은 취약하다. 법령 제정을 통해 공중보건의 정 체성을 확립하고 공중보건 분야에 종사하는 전문 인력을 양성해 나가야 한다. 그리고 이 법을 통해 개별법에 의해 추진 되는 지역보건, 학교보건, 산업보건, 환경보건 등을 어떻게 연결할 것인지 교통정리를 한다면 금상첨화일 것이다.

\section{참고문헌}

김혜경. 공중보건의료 분야에서의 의사역량 강화방안 : 공공보건 분야 교육·훈련 방안을 중심으로. 의료정책포럼. 2016:14(1):47-52

김혜경. 현장에서 바라보는 공공보건인력(의사)의 핵심역량. 2016 대한공공의학회 춘계학술대회 발표자료

김혜경. 공중보건 전문 인력의 핵심역량 제안. 2017.04.08. 대한보건협회 종합학술대회 발표자료

김혜경. 공중보건 전문 인력의 책무와 핵심역량. 2017.07.10. 경기도 공공병원과 보건소간 발전방향 모색을 위한 보건소 공공보건의료분야 토론 회 발표자료

보건의료기본법

공공보건의료에 관한 법률

지역보건법

정신건강증진 및 정신질환자 복지서비스 지원에 관한 법률

의료법 